\title{
Achik-Kerib (história turca)
}

\author{
M. I. Lérmontov \\ Tradução de BORIS SCHNAIDERMAN*
}

Muitos anos atrás, na cidade de Tíflis vivia um turco rico; Alá lhe deu muito ouro, porém mais valioso que o ouro era sua filha única Magul-Meguéri: são belos os astros do céu mas atrás dos astros vivem anjos que são ainda mais belos e assim Magul-Meguéri era a mais bela das jovens de Tŕflis. Vivia também em Tŕflis o Pobre Achik-Kerib; o profeta não lhe dera nada além de um grande coração e o dom das cançōes. Tocando saaz e celebrando os antigos cavaleiros do Turquestão ele ia de um casamento a outro, para alegrar os ricos e felizes; num desses casamentos ele viu Magul-Meguéri e eles se apaixonaram. O pobre Achik tinha pouca esperança de obter a sua mão, e se tornou tão triste como um céu de inverno.

Um dia ele estava deitado num vinhedo e finalmente adormeceu; nessa hora passaram por ele Magul-Meguéri e suas amigas; uma delas ao ver o Achik adormecido, ficou para trás e aproximou-se dele: " Por que ficas dormindo embaixo de uma videira - cantou ela - levanta-se insano, a tua gazela está passando"; ele acordou e a moça fugiu como um passarinho; Magul-Meguéri tinha ouvido a sua canção e começou a censurá-la: "Se tu soubesses - respondeu a outra - a quem cantei esta canção me agradecerias: é o teu Achik-Kerib"; "Leva-me até ele" - disse Magul-Meguéri; e elas foram. Vendo seu rosto tristonho Magul-Meguéri começou a interrogá-lo e a consolar: "Como não vou me entristecer - respondeu Achik-Kerib -, eu te amo e tu nunca serás minha". "Pede a minha mão a meu pai e meu pai vai celebrar nosso casamento com o dinheiro dele e me dará tanto que será o suficiente para nós dois". "Está bem - respondeu ele -, admitamos que Aian-Agá não poupe nada para sua filha; mas quem sabe se depois tu não vais me censurar porque eu não tinha nada e fiquei te devendo tudo. Não, minha doce Magul-Megueri; eu coloquei um penhor sobre a minha alma; comprometo-me a peregrinar sete anos pelo mundo, conseguir riquezas ou morrer nos desertos distantes; se concordas com isso, decorrido esse prazo serás minha". Ela concordou, mas acrescentou que se no dia marcado ela não voltasse, ela se tornaria esposa de Kurchud-Bek, que há muito pedia sua mão.

Achik-Kerib foi ter com sua mãe; tomou a benção, beijou a irmãzinha, pendurou no ombro uma bolsa, apoiou-se num cajado de peregrino, e saiu da cidade de Tŕflis. E eis que um cavaleiro o alcança e ele vê que é Kurchud-Bek. "Boa viagem - grita-lhe Bek aonde quer que vás, peregrino, sou teu amigo"; Achik não ficou contente de ver o amigo mas não havia nada a fazer; caminharam juntos por muito tempo até que encontraram um rio. Nem ponte nem vau; "Nada na frente - disse Kurchud -, eu vou te seguir". Achik tirou a roupa e nadou; chegando à outra margem, olhou para trás e - Oh desgraça! Oh Alá onipotente! Kurchud-Bek tinha apanhado a sua roupa, galopando de volta a Tf́flis e somente a poeira turbilhonava atrás dele, feito cobra em campo liso.

Kurchud-Bek leva a roupa de Achik a sua velha mãe: "Teu filho se afogou no rio profundo, aqui está sua roupa"; numa angústia indescrit́vel, a mãe caiu sobre a roupa do filho amado e passou a molhá-la com lágrimas ardentes; depois apanhou-a e levou à
- A pontuaçáo foi conservada, aproximadamente, como no original russo. 
sua noiva prometida Magul-Meguéri. "Meu filho se afogou - disse ela - Kurchud-Bek trouxe a roupa dele; estás livre". Magul-Meguéri sorriu e respondeu: "Não acredites; tudo são invenções de Kurchud-Bek; antes que passem sete anos ninguém será meu esposo". Ela tirou da parede o saaz e começou a cantar tranqüilamente a canção predileta do pobre Achik-Kerib.

Neste ínterim, o peregrino chegou descalço e nu a uma aldeia; gente boa vestiu-o e alimentou-o; ele, para recompensá-los, cantou umas canções maravilhosas; assim foi passando de aldeia em aldeia, de cidade em cidade, e sua fama se espalhou por toda parte. Chegou finalmente a Khalaf; como de costume, entrou num café, pediu um saaz e pôs-se a cantar. Nesta época vivia em Khalaf um paxá, grande apreciador de cantores; muitos foram levados a sua presença mas ele não gostou de nenhum; os seus servos se esfalfaram, correndo pela cidade; de repente, passando por um cafe, ouviram uma voz surpreendente; eles então: "Vem conosco à presença do grande paxá - gritaram -, ou vais responder com a tua cabeça". "Eu sou um homem livre, peregrino da cidade de Trflis - se quiser irei, se não quiser, não. Canto quando me dá na veneta e o vosso paxá não é o meu chefe."

Apesar disso, eles o agarraram e o levaram à presença do paxá. "Cante" - disse o paxá, e ele cantou e nessa canção ele celebrava a sua querida Magul-Meguéri; e essa canção agradou tanto ao orgulhoso paxá que ele deixou em seu palácio o pobre AchikKerib. Ouro e prata choveram sobre ele, brilharam nele ricos trajes; Achik-Kerib passou a viver em felicidade e alegria e tornou-se muito rico. Se ele esqueceu ou não a sua Magul-Meguéri, não sei, mas o tempo ia correndo, o último ano estava próximo do fim, e ele nem se preparava para a partida. A formosa Magul-Meguéri começou a desesperar: nesse tempo, um mercador estava saindo com uma caravana de Tiflis, com quarenta camelos e oitenta escravos: ela chama o mercador à sua casa, e lhe dá uma bandeja de ouro: "Toma esta bandeja - diz ela - e em qualquer cidade que chegues expõe a bandeja em tua venda e declara em toda parte que aquele que se declarar dono da bandeja há de recebê-la, e de sobra o seu peso em ouro". Partiu o mercador e em toda parte cumpria o encargo de Magul-Meguéri, mas ninguém se declarava dono da bandeja de ouro. Ele já tinha vendido quase toda a mercadoria e chegou com as restantes a Khalaf e proclamou em toda a parte a incumbência de Magul-Meguéri. Ouvindo isso Achik-Kerib chega correndo ao caravançará e vê a bandeja de ouro na venda do mercador de Tíflis. "É minha" - disse ele agarrando-a com a mão. "Está certo, é tua - disse o mercador. Eu te reconheci, Achik-Kerib: vai o quanto antes a Tŕflis, a tua Magul-Meguéri mandou te dizer que o prazo está terminando, e que se não chegares no dia marcado, ela se casará com outro". Desesperado, Achik-Kerib agarrou a cabeça: faltavam apenas três dias para a hora fatal. No entanto, pulou sobre o cavalo, levou consigo uma bolsa com moedas de ouro e galopou sem pena do animal. Finalmente, extenuado, o cavalo caiu sem forças na montanha de Arzinhan que fica entre Arzinhan e Arzerum. Que fazer? De Arzinhan a Tíflis são dois meses de viagem e faltavam apenas dois dias. "Alá onipotente! - exclamou ele - se tu já não me ajudas, não tenho mais o que fazer sobre a terra". E ele quis se atirar de um alto penhasco; de repente, vê em baixo um homem montado num cavalo branco e ouve uma voz sonora: "Oglan, o que queres fazer?" "Quero morrer" respondeu Achik. "Desce para cá se é assim e eu te mato". Achik desceu como pôde do penhasco. "Segue-me" - disse ameaçador o cavaleiro; "Como posso te seguir? O teu cavalo voa que nem o vento e eu tenho comigo uma bolsa pesada"; "Pendura a bolsa na minha sela e segue-me"; Achik-Kerib ficou para trás, por mais que procurasse correr. "Por que te atrasas?" - perguntou o cavaleiro; "Como posso seguir-te, teu cavalo é mais veloz que o pensamento e eu já estou extenuado". "É mesmo, senta-te atrás do meu cavalo e dize toda a verdade, para onde precisas ir". "Pelo menos chegar hoje a Arzerum" -, respondeu Achik. "Fecha os olhos"; e ele fechou. "Agora abre"; e Achik vê: diante dele, branquejam as muralhas e brilham os minaretes de Arzerum.

"Desculpe Agar, eu me enganei - disse Achik -, eu queria dizer que precisava ir a Kars". "Ora, ora - respondeu o cavaleiro -, eu te avisei que me dissesses a pura verdade. Fecha os olhos e agora abre"; Achik não acredita mas está vendo Kars; ele caiu de joelhos e disse: "Perdão Agar, três vezes sou culpado, teu criado Achik-Kerib, mas tu sabes que se um homem decidiu mentir de manhã ele tem de ficar mentindo o dia todo. $\mathrm{Na}$ verdade, eu preciso ir a Tíflis". "Como és infiel - disse zangado o cavaleiro - mas não há o que fazer, eu te perdôo: fecha os olhos e agora abre" - acrescentou ele, passado um momento. Achik soltou um grito de alegria: eles estavam às portas de Tíflis. Expressando sua gratidão sincera e apanhando da sela a sua bolsa, Achik disse ao cavalei- 
ro: "Agora, está claro que foi grande a tua dádiva mas faze ainda mais. Se eu agora contar que, num dia, pude me transportar de Arzinhan a Tíflis, ninguém me acreditará. Dá-me alguma prova". "Inclina-te - disse o outro com um sorriso - e apanha sob o casco do cavalo um punhado de terra, coloca-o embaixo da camisa e, então, se não acreditarem na verdade das tuas palavras, manda que levem a tua presença uma cega, que está há sete anos nesta condição, passa-lhe terra nos olhos e ela verá". Achik apanhou um punhado de terra embaixo do casco do cavalo branco, mas apenas levantou a cabeça, o cavalo e o cavaleiro desapareceram; e então ele se convenceu, no íntimo, de que seu protetor não era outro senão Khadrilhez (São Jorge).

Só tarde da noite Achik-Kerib encontra a sua casa; ele bate à porta com a mão trêmula, dizendo: "Ana, Ana (mãe), abre, sou o hóspede de Deus; tenho frio e tenho fome; peço-te em nome de teu filho peregrino, deixa-me entrar". A voz fraca da velha respondeu-lhe: "Para abrigo dos peregrinos existem as casas dos ricos e dos fortes: ocorrem agora na cidade casamentos. Vai, ali podes passar a noite a bel-prazer". "Ana - respondeu ele -, eu aqui não conheço ninguém e por isso repito meu pedido: em nome de teu filho peregrino, deixa-me entrar". Então a irmã dele diz à mãe: "Mãe, vou me levantar e abrir-lhe a porta". "Moça sem valia - respondeu a velha - ficas contente de receber homens jovens e alimentá-los, porque já faz sete anos que eu de tanto chorar perdi a vista". Mas a filha sem atentar às suas censuras ergueu-se, abriu a porta e deixou entrar Achik-Kerib: dizendo a saudação usual, ele sentou-se e com perturbação secreta pôs-se a examinar tudo. E viu que estava suspenso na parede, num estojo empoeirado, o seu saaz de doces sons. E ele se pôs a perguntar à mãe: "O que tens aí pendurado na parede?" "Hospede curioso - respondeu ela. Basta que recebas um pedaço de pão, e que amanhã te deixem ir com Deus". "Eu já disse - replicou ele - que és a minha própria mãe e esta é minha irmã e por isso eu peço explicarem-me: O que está suspenso af na parede?" "É o saaz, o saaz" - respondeu a velha zangada sem acreditar. "E o que quer dizer saaz?" "Saaz significa que nele se tocam e se cantam canções". Pede, então, Achik, que ela permita à irmã tirar o saaz da parede e mostrar-lhe. "Impossível respondeu a velha. É o saaz de meu infeliz filho; já faz sete anos que ele está pendurado na parede e mão viva nenhuma tocou nele". Mas a irmã se levantou, tirou da parede o saaz e lhe entregou: então ele ergueu os olhos ao céu e proferiu a seguinte oração: "Oh Alá onipotente! Se eu tenho de atingir o fim almejado, o meu saaz de sete cordas será tão sonoro como no dia em que toquei nele pela última vez". E ele tocou nas cordas de cobre e as cordas falaram de acordo, e ele se pôs a cantar: "Sou o pobre Kerib (mendigo) e as minhas palavras são pobres; mas o grande Khadrilhez ajudou-me a descer do penhasco abrupto, embora eu seja pobre e pobres minhas palavras. Reconheceme, mãe, o teu peregrino". A mãe se põe a chorar e pergunta-lhe: "Como te chamas?" "Rachid (valente) - respondeu ele - uma vez fala, outra vez escuta". "Rachid - disse ela - com as tuas falas me cortaste o coração em pedaços. Esta noite, vi em sonho que em minha cabeça os cabelos embranqueceram, e já faz sete anos que ceguei de tanto chorar. Dize-me tu, que tens a tua voz, quando meu filho voltará?" E duas vezes repetiu em lágrimas aquele pedido. Era em vão que ele se nomeava como seu filho, ela não acreditava e, decorrido algum tempo, ele pediu: "Permita-me, mãezinha, apanhar o saaz e sair, ouvi dizer que há um casamento aqui perto: minha irmã vai me acompanhar; vou cantar e tocar, e tudo o que eu receber vou trazer para cá e repartir convosco". "Não vou permitir" - respondeu a velha. Desde que meu filho não está aqui, o seu saaz não saiu de casa". Mas ele passou a jurar que não danificaria nenhuma corda. "E se uma corda se romper - prosseguiu Achik -, eu vou responder com tudo o que possuo". A velha apalpou as suas bolsas e, percebendo que elas estavam repletas de moedas, deixou-o que fosse; acompanhando-o até a casa rica onde ressoava o festim de bodas, a irmã ficou à porta, para ouvir o que ia acontecer. Nessa casa vivia Magul-Meguéri, e nessa noite ela deveria tornar-se esposa de Kurchud-Bek, que celebrava um festim com seus familiares e amigos, e Magul-Meguéri, sentada atrás de uma rica tchaprá (reposteiro), com suas amigas, tinha numa das mãos uma taça com veneno e na outra um punhal afiado: ela jurara morrer antes de pousar a cabeça no leito de Kurchud-Bek. E ela ouve detrás do reposteiro que chegou um desconhecido que disse: "Seliam Aleicum, estais aqui festejando e alegrando-vos, então permiti-me, pobre peregrino, sentar-me convosco e eu lhes cantarei uma canção". "Por que não? - disse Kurchud-Bek. Devem deixar entrar aqui cantadores e dançarinos, porque aqui se celebra um casamento. Canta-nos alguma coisa, Achik, e eu te deixarei ir com todo um punhado de ouro".

Então Kurchud-Bek the perguntou: "Como te chamas, caminhante?" Shindi Gorur-

Eetembro 
sez” (logo sabereis). "Que nome é esse? - exclamou o outro rindo. É a primeira vez que eu ouço". "Quando minha mãe estava grávida de mim e sofreu para me dar à luz, muitos parentes chegavam até a sua porta para saber se Deus lhe dera um filho ou uma filha: respondia-lhe shindi gorursez e por isso quando eu nasci deram-me este nome". Depois disso, ele apanhou o saaz e começou a cantar.

"Na cidade de Khalaf eu tomava vinho de Misr**, mas Deus me deu asas e eu vim voando para cá num só dia".

O irmão de Kurchud-Bek, homem de juízo limitado, arrancou o punhal e exclamou: "Mentes; como é possível vir de Khalaf para cá num só dia?" "Mas por que tu queres me matar? - disse Achik - os cantores são geralmente reunidos dos quatro cantos num só lugar e eu não lhes cobro nada, quer me acrediteis, quer não". "Que ele continue" disse o noivo e Achik-Kerib tornou a cantar.

"Procedi à unção matinal no vale de Arzinhan e à unção de meio-dia na cidade de Arzerum; antes do pôr-do-sol procedi à unção na cidade de Kars e à da noite em Tíflis. Alá me deu asas, vim para cá voando; antes eu me tornasse vítima, por vontade de Deus, do cavalo branco. Ele galopava depressa, como um dançarino sobre a corda, da montanha para os vales e dos vales para a montanha: Mauliam (o criador) deu asas a Achik e ele chegou voando para o casamento de Magul-Meguéri".

Conhecendo então sua voz, Magul-Meguéri atirou o veneno para um lado e o punhal para o outro. "Então tu cumpriste o teu juramento - disseram as suas amigas -, quer dizer que à noite serás esposa de Kurchud-Bek". "Vós não reconhecestes mas eu reconheci a voz que me é querida" - respondeu Magul-Meguéri e, apanhando uma tesoura, ela cortou a tchaprá. E quando olhou e reconheceu o seu Achik-Kerib, soltou uma exclamação; atirou-se ao seu pescoço e ambos caíram sem sentidos. $\mathrm{O}$ irmão de KurchudBek lançou-se sobre eles com um punhal, pretendendo apunhalar a ambos, mas Kurchud-Bek o deteve acrescentando: "Acalma-te e fica sabendo: o que está escrito na fronte de um homem ao nascer, ele nunca poderá evitar".

Voltando a si, Magul-Meguéri ficou vermelha de vergonha, ocultou o rosto com a mão e escondeu-se atrás da tchaprá.

"Agora se vê bem que és Achik-Kerib - disse o noivo. Mas pensa bem, como pudeste num tempo tão curto atravessar um espaço tão vasto?" "Como prova da verdade respondeu Achik-Kerib - o meu sabre quebrará a pedra, mas se eu minto que o meu pescoço seja mais fino do que um fio de cabelo; mas o melhor de tudo é me trazerdes uma cega que há sete anos não tenha visto a luz de Deus e eu lhe devolverei a visão". A irmã de Achik-Kerib, que estava junto à porta, ao ouvir esta fala, correu para junto da mãe: "Mãezinha, ele é de fato meu irmão, é o teu filho Achik-Kerib"; e, tomando-a pela mão, conduziu-a ao festim de bodas.

Então Achik apanhou sob a camisa o punhado de terra, colocou-o na água e untou com ele os olhos de sua mãe, acrescentando: "Saibam todos quanto Khadrilhez é grande e poderoso"; e sua mãe voltou a enxergar. Depois disso, ninguém ousou duvidar da verdade de suas palavras e Kurchud-Bek cedeu-lhe sem dizer nada a bela Magul-Meguéri.

Então Achik-Kerib lhe disse com alegria: "Ouve, Kurchud-Bek, eu vou te consolar: minha irmã não é pior que a tua ex-noiva. Eu sou rico: ela não terá menos prata e ouro; pois bem, toma-a para ti e sede tão felizes quanto eu com a minha querida Magul-Meguéri". 